\title{
EVALUATION OF THREE DIFFERENT TECHNIQUES IN PREVENTION AND TREATMENT OF EARLY ENAMEL DECALCIFICATION
}

\author{
Abbas R. Zaher ${ }^{1}$, Nadia M. El-Harouni ${ }^{1}$, \\ Sahar M. El-Sheikh² and Alaa A. Elshafei ${ }^{3}$
}

\section{ABSTRACT:}

Objectives: This study was designed to evaluate and compare the effect of two commercially available casein phosphopeptide amorphous calcium phosphate preparations applied with or without stannous fluoride gel in the prevention and treatment of early enamel decalcification.

Materials and methods: The material consisted of eighty freshly extracted premolars which were divided into 8 equal groups of 10 each. Four groups were used to evaluate the effectiveness of Tooth Mousse, Tooth Mousse combined with stannous fluoride gel and Topacal C-5 combined with stannous fluoride gel in the prevention of enamel demineralization around orthodontic brackets, using polarized light microscope. The other four groups were used to evaluate the effect of the same three techniques in the treatment of artificially induced white spot lesions, using stereomicroscopic imaging.

Results: The teeth in the control group had the deepest lesions followed by the Tooth Mousse then the two combination groups. Similarly teeth which showed an improvement in the severity of the white spot lesions from the baseline scoring were only in the

\footnotetext{
${ }^{1}$ Professor, Department of Orthodontics, Faculty of Dentistry, Alexandria University.

${ }^{2}$ Assistant Professor, Department of Oral Pathology, Faculty of Dentistry, Alexandria University.

${ }^{3}$ Graduate Student, Department of Orthodontics, Faculty of Dentistry, Alexandria University.
} 
test groups and the complete healing was only in the two combination groups, while worsening of white spots to white spots with cavitation was mainly seen in the control group.

Conclusions: The three tested techniques proved to be able to reduce the rate of enamel demineralization around orthodontic brackets when compared with the control (no treatment). The three tested techniques proved to be able to treat the white spot lesions to a limited extent and to prevent their worsening into cavitations when compared with the control (no treatment). There were no statistically significant differences between the effects of the tested techniques neither in the prevention of enamel demineralization nor in the treatment of the white spot lesions.

\section{INTRODUCTION}

Esthetic enhancement is the major objective of any orthodontic treatment plan. Unfortunately early enamel decalcifications, in the form of white spots, develop in some patients during orthodontic treatment with fixed appliances. ${ }^{(1)}$ Enamel decalcification is attributed to the mechanical difficulty which hinders proper tooth cleaning \& favors plaque retention. ${ }^{(2)}$ New and often extensive pattern of plaque accumulation is associated with resin bonded orthodontic brackets, which in turn increase the risk of enamel decalcification or white spots formation. White spots or areas of decalcification are early carious lesions of varying extent. They also vary in their incidence from one individual to another and in the same person from one surface to another. ${ }^{(1,3,4)}$

Early detection of patients with increased risk for decalcification is possible by the use of different related indices including caries and plaque indices. Patients with low risk require only diet counseling, regular patient motivation and fluoridation. However in patients with elevated risk more extensive measures of prophylaxis are required. These measures include mechanical tooth cleaning by professional dental hygienist, scaling, irrigation of subgingival pockets and chlorhexidine application. ${ }^{(5)}$ In order to diminish the white spots problem associated with resin bonded brackets several preventive methods were presented. 
These methods include oral hygiene instructions, electric tooth brushes and oral irrigating systems, ${ }^{(6)}$ chemical plaque removal, ${ }^{(7)}$ chewing gum, ${ }^{(8)}$ antimicrobial varnish, ${ }^{(9,10)}$ pit and fissure sealing, ${ }^{(2,11)}$ as well as argon laser irradiation, ${ }^{(12)}$ in addition patient ranking according to its susceptibility to enamel decalcification which help in determining the suitable prophylactic regimen for that particular patient ${ }^{(13)}$

To date fluoride has played the major role in prevention of demineralization during orthodontic treatment. Fluorides can be applied using several methods, such as professional topical fluoride application, ${ }^{(14,15)}$ self applied gel, ${ }^{(16-18)}$ and fluoride rinse, ${ }^{(19-21)}$ fluoride releasing elastomeric modules, ${ }^{(22,23)}$ fluoride releasing varnish, ${ }^{(24,25)}$ and bonding brackets and bands using fluoride releasing glass ionomer cement ${ }^{(26,27)}$ or fluoride releasing composite. ${ }^{(28)}$ The diversity of published data makes it difficult for the clinician to determine which vehicle or combination of topical fluoride preparations is most effective. Different preparations and formats appear to decrease decalcification, but there was no evidence that any specific method was superior. ${ }^{(29)}$

Casein-phosphopeptide amorphous calcium-phosphate (CPP-ACP) complex was recently used for protecting enamel surface. ${ }^{(30)}$ All the CPP-ACP formulas are based upon the milk protein casein. Milk and milk products proved to have anticariogenic effect in several studies ${ }^{(31,32)}$. All these studies showed that the casein, calcium and phosphate are the components of milk that are able to provide protection and remineralization of the tooth enamel layer ${ }^{(33)}$. CPP-ACP formulas proved to be effective in reducing caries activity when applied in several forms such as solutions ${ }^{(34)}$ and pastes $^{(35,36)}$ or when incorporated into chewing gum ${ }^{(37)}$ or glass ionomer cement $^{(38)}$.

The aim of the study was to compare the efficiency of the two CPP-ACP preparations Tooth Mousse and Topacal C-5 used in combination with home care $0.04 \%$ stannous fluoride gel and of Tooth Mousse applied alone in the prevention and treatment of early enamel decalcification.

\section{Materials and Methods:}

The material of the study consisted of 80 human premolar teeth extracted for orthodontic purposes. The teeth were sound and free from caries or any sign of decalcification. The enamel showed neither visible 
developmental defects nor fracture lines. The teeth were cleaned by removal of calculus, bone and soft tissues using a scaler. The teeth were then rinsed under running water and stored in $10 \%$ formaldehyde in saline solution till the start of the study to avoid dehydration.

At the onset of the study, the teeth were thoroughly washed from the formaldehyde solution under running water then dried with moisture and oil free air. The enamel surface of each tooth was polished with a rubber prophylaxis cup at low speed with a mixture of non-fluoridated pumice and water then the teeth were again thoroughly rinsed. A hole was drilled near the apex of the root of each tooth by the use of a fissure bur on a high speed hand piece. Through that hole the tooth was hanged by a ligature wire to facilitate its handling during application of different preparations and in the transfer from one solution to another. The ligature wire also carried the label of each tooth according to its group.

All through the study the teeth were cycled between an artificial saliva solution for 11 hours and an artificial caries solution for 1 hour twice a day. This was repeated for 35 days in part one and for 30 days in part two of the study. The artificial saliva solution used in the study consisted of $20 \mathrm{mmol} / \mathrm{L} \mathrm{NaHCO}_{3}, 3 \mathrm{mmol} / \mathrm{L} \mathrm{NaH}_{2} \mathrm{PO}_{4}, 1 \mathrm{mmol} / \mathrm{L} \mathrm{CaCl}$ at neutral $\mathrm{pH}^{(7)}$, while the artificial caries challenge solution used in the study consisted of $2.2 \mathrm{mmol} / \mathrm{L} \mathrm{Ca}^{+}, 2.2 \mathrm{mmol} / \mathrm{L} \mathrm{PO}_{4}{ }^{-3}, 50 \mathrm{mmol} / \mathrm{L}$ acetic acid at acidic $\mathrm{pH}^{(5)}$.

The teeth were then divided into two groups each consisting of 40 teeth and the study was carried out in two parts:

Part I: 40 premolar teeth were used to evaluate the efficiency of Tooth Mousse*, Tooth mousse combined with Home Care stannous fluoride gel ${ }^{* *}$ and Topacal C-5* combined with Home Care stannous fluoride gel in the prevention of enamel demineralization around the directly bonded orthodontic brackets.

\footnotetext{
* GC Tooth Mousse. GC corporation Tokyo Japan.

** Home Care Fluoride Treatment Gel, 0.4\% Stannous Fluoride, Alpha-Dent, USA.

- Topacal C-5, Enamel Improving Cream, NSI Dental Pty Ltd, Australia.
} 
A window in the size of an orthodontic bracket base was cut out from a piece of adhesive tape that was used to wrap the tooth. The window centered on the facial surface (Fig 1)and prevented unintentional etching of enamel surface beyond the area receiving the bracket base The exposed area of the enamel surface was etched with $37 \%$ orthophosphoric acid gel for 30 seconds, then rinsed with water for 30 seconds and thoroughly dried with moisture and oil free air stream.

Standard edgewise metal premolar brackets ${ }^{\Omega}$ were bonded to all the teeth using chemically cured non-fluoride releasing composite resin ${ }^{\#}$ following the manufacturer's instructions. The brackets were placed with firm pressure and excess resin flash was removed from around the bracket base with a dental scaler. Twenty minutes after bonding, the adhesive tape was removed The teeth were then coated with a layer of nail polish covering the whole tooth surface except a $2 \mathrm{~mm}$ zone around the bracket base.

The forty bracketed teeth were then subdivided into four equal groups of ten each and treated as follows:

Group 1: The exposed enamel zone of each tooth was treated once daily with Tooth Mousse using a tooth brush in a circular motion for 5-10 seconds. Then the tooth was placed again in the saliva solution without washing according to the manufacturer recommendations.

Group 2: The exposed enamel zone of each tooth was treated once daily with stannous fluoride gel using a tooth brush in a circular motion for 5-10 seconds followed by once daily application of Tooth Mousse using a tooth brush in a circular motion for 5-10 seconds then returned back to the saliva solution without washing according to the manufacturer recommendations to the saliva solution without washing according to the manufacturer recommendations.

Group 3: The exposed enamel zone of each tooth was treated twice daily with Topacal C-5 using tooth brush in a circular motion for 5-10 seconds then returned back to the saliva solution without washing

\footnotetext{
$\Omega$ American Orthodontics, USA

\#3M Unitek, 3M company USA
} 
according to manufacturer recommendations. One of the two applications of the Topacal C-5 was preceded by once daily application of stannous fluoride gel using a tooth brush in a circular motion for 5-10 seconds.

Group 4: The control group did not receive any further treatment during the study.

Each group was stored in a separate beaker containing $200 \mathrm{ml}$ of artificial saliva solution. After 12 hours, cycling between artificial saliva and artificial caries challenge solution was initiated as follows; 1 hour in the caries solution followed by 11 hours in the saliva solution. Both solutions were stored at room temperature and changed every 3 days. The previously mentioned topical applications and cycling was carried out for 35 days then all the teeth were removed from saliva solution, dried thoroughly then the brackets debonded.

Rotary grinding of the teeth was carried out longitudinally in a mesiodistal direction using a water cooled diamond disk. Further thickness reduction was carried out by grinding the longitudinal sections on a polishing board until a thickness of $100 \mu \mathrm{m}$ was obtained. The sections were then washed with de-ionized water and mounted longitudinally on glass cover slides. The sections of the four groups were then examined under polarized light microscope (PLM) and photographed with $50 \mathrm{X}$ magnification.

On the PLM pictures the enamel surface and the full depth of the lesions where pseudo isotropy occurred were traced on a tracing paper. For depth measurement calculations on the tracing of the PLM pictures; 3 lines from the enamel surface and perpendicular to it were drawn. The lines extended to the deepest point of the lesion. The tracings were scanned into a computer using a light scanner. The three lines were measured for each section by the use of a computer software program (AutoCAD 2004) and the mean depth calculated. The actual depth was calculated in mm using a 1:50 scale and then converted into $\mu \mathrm{m}$ by multiplying it by $10^{3}$. The accuracy of the software program was calibrated by measuring the three lines on three different tracings using a digital caliber and comparing it with those obtained from the software program. The area of the lesion between these three depth measurements 
was calculated by the use of the same computer software program (AutoCAD 2004). The actual area was calculated in $\mathrm{mm}^{2}$ using a 1: 2500 scale and then converted into $\mu \mathrm{m}^{2}$ by multiplying by $10^{6}$. Descriptive statistics of depth and area of demineralization were displayed in the form of mean \pm SD. Comparison of mean depth and mean area of demineralization among groups was done using one way analysis of variance followed by Tukey post hoc pairwise comparison.

Part II: The other 40 premolar teeth were used to compare the efficiency of Tooth Mousse, Tooth mousse combined with Home Care stannous fluoride gel and Topacal C-5 combined with Home Care stannous fluoride gel in the treatment of the artificially induced enamel white spot lesions.

The teeth were cleaned and polished as fore mentioned. Each tooth was wrapped in an adhesive tape with a small window centered on the buccal surface. The teeth were then immersed in an artificial caries solution for 3 weeks until visible white spots were formed. The adhesive tapes were removed and the teeth washed under running water for 1 minute and then dried with moisture and oil free jet of air for 15 seconds. The teeth were then examined visually and photographed by stereomicroscope.

The assessment of the degree of the white spots was carried out by the use of a scoring system

Score 0 no visible white spot

Score 1 slight visible white spot

Score 2 excessive visible white spot

Score 3 white spot formation with cavitation

All the teeth had a base line score of 2 (Excessively visible white spot) after being removed from the decalcifying solution and before application of any treatment.

The sample of forty premolars was subdivided into four equal groups of ten each Specimens in Groups 1, 2, 3 were treated with the remineralizing preparations as previously described. 
- Group 4: The control group did not receive any further treatment..

The four groups were stored in separate beakers containing $200 \mathrm{ml}$ of artificial saliva solution for 11 hours and cycled with artificial caries solution for 1 hour twice per day. The teeth were then re-examined visually and photographed by stereomicroscope after 2 weeks and then 4 weeks of cycling and application of topical preparations. The change in the scoring of white spots in each of the study groups over time was compared using Wilcoxon Signed Rank tests. The chi square test was also used to compare the severity of white spot lesions among the four groups at different follow up periods followed by comparison of proportions to compare score differences between pairs of groups.

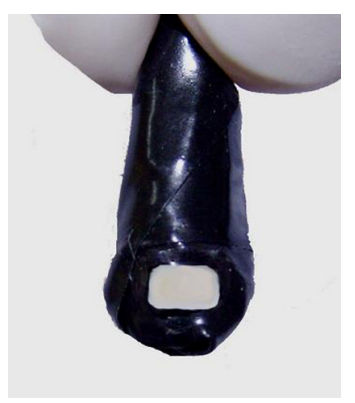

Fig 1: The tooth wrapped with an adhesive tape leaving a window the size of an orthodontic bracket base

\section{RESULTS}

The results of this study will be presented on two sections:

Evaluation of the effectiveness of the three techniques in the prevention of enamel demineralization through examination of PLM pictures of the slides of the different groups:

\section{a) Descriptive evaluation:}

1) The Control group: had the largest enamel lesion depth. These lesions were represented by the increased birefringence (double refraction) in the form of different zones having heterogeneous colors extending from the surface deep into the enamel layers. The lesion birefringence then merges with the normal birefringence of the intact enamel which 
appears grey. In some sections the lesions extended to involve the whole enamel thickness (Fig 2)

2) The Tooth Mousse group: the lesions showing increased birefringence were less deep than in the Control group. (Fig 3).

3) Sections of the Topacal C-5/fluoride group showed enamel decalcification lesions i.e.layers which showed increased birefringence less thick than in the Control and the Tooth Mousse group. Also the merge with the normal enamel birefringence was more superficial than the previous two groups. Some portions of the enamel near the surface showed return of the normal birefringence of the sound enamel (grey) indicating a starting enamel remineralization (Fig 4).

4) Tooth Mousse/fluoride group: The sections of this group showed the least thickness of the enamel decalcification lesions. This was represented under PLM by reduction of the thickness of the layers that showed increased birefringence when compared with the previous three groups. The sections of this group also showed more superficial merge of the subsurface lesions with normal enamel and wider areas with starting remineralization (Fig 5).

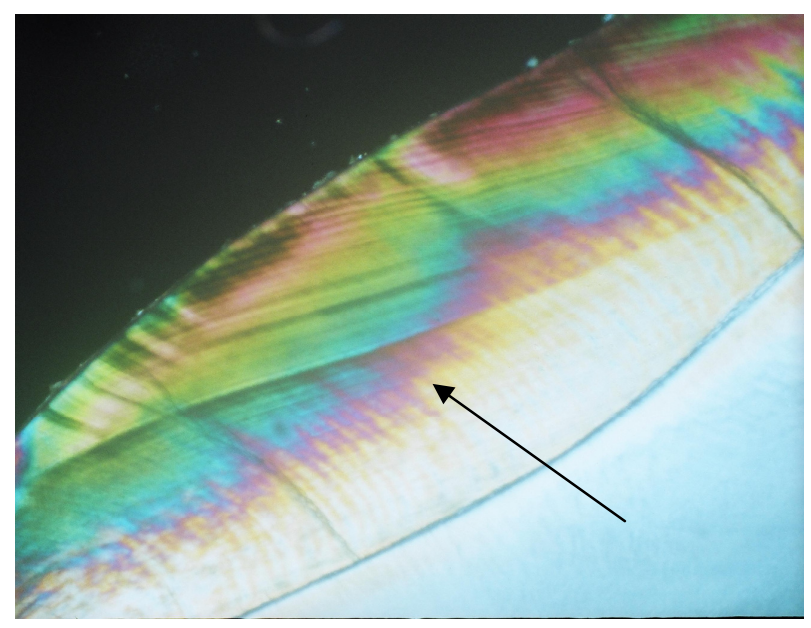

Fig 2: PLM picture of a section in the Control group (with 50X magnification) showing the increased birefringence extending deep into the enamel before merging with the normal enamel birefringence (arrow). 


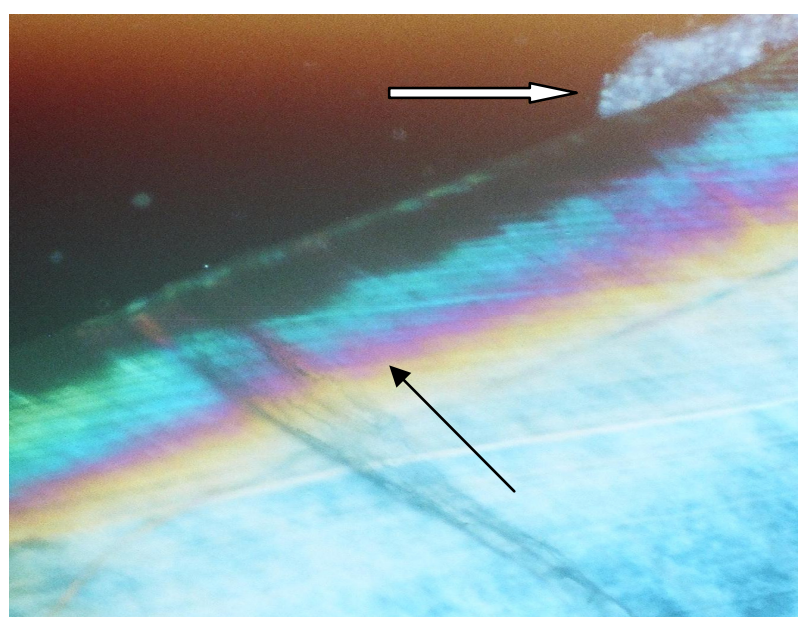

Fig 3: PLM picture of a section in the Tooth Mousse group (with 50X magnification) showing the increased birefringence extending to a lesser extent into the enamel before merging with the normal enamel birefringence(black arrow), remnants of composite resin is also seen on enamel surface (white arrow).

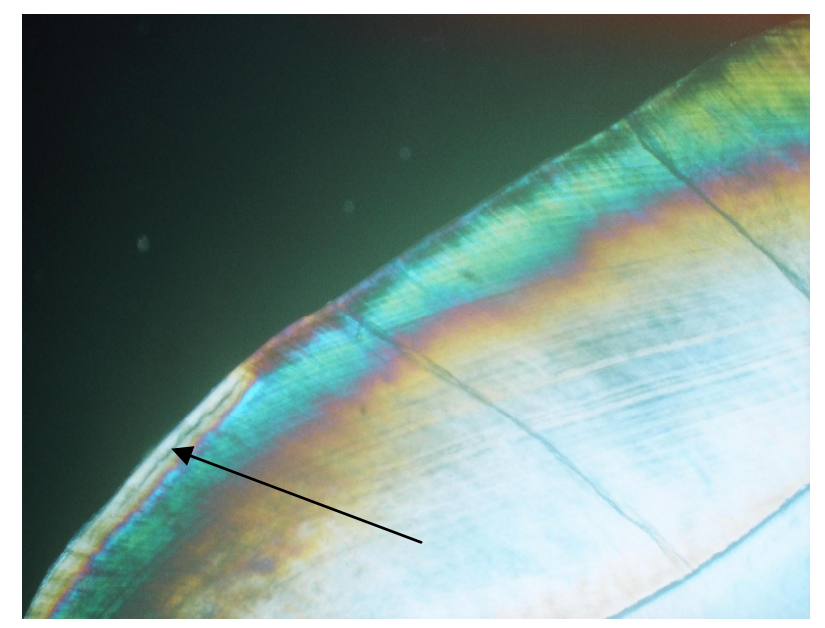

Fig 4: PLM picture of a section in the Topacal C-5/fluoride group (with 50X magnification) showing the increased birefringence merging more superficially with the normal enamel birefringence and area of remineralization (arrow). 


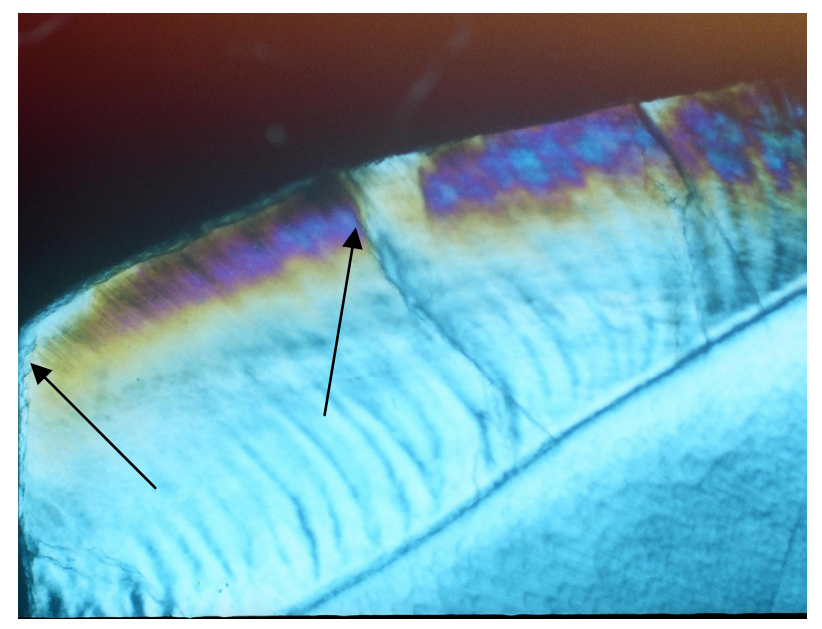

Fig 5: PLM picture of a section in the Tooth Mousse/fluoride group (with 50X magnification) showing the increased birefringence merging more superficially with the normal enamel birefringence and areas of remineralization (arrows)

\section{b) Geometric evaluation of the depth and area of the subsurface} demineralization lesions:

The Control group showed the deepest lesions followed by the Tooth Mousse group then the Topacal C-5/fluoride group while the Tooth Mousse/fluoride group showed the least depth of demineralization (648.03, 468.27, 357.93 and 341.40 respectively). Similarly the largest mean area of demineralization was found in the Control group followed by the Tooth Mousse group then the Topacal C-5/fluoride group, while the Tooth Mousse/fluoride group showed the smallest mean area of demineralization $(258.15,174.80,144.26$ and 142.98 respectively). The differences of the mean depth and area of demineralization among the four groups was statistically significant. The pairwise comparison of mean lesion depth and area among the four groups showed that there were statistically significant differences between the Control group and all the test groups but no differences were found between the test groups (Tables 1\&2). 
Table 1: Basic statistics showing the comparison of the mean depth of demineralization in $\mu \mathrm{m}$ between the four study groups.

\begin{tabular}{|l|c|c|c|c|}
\hline \multicolumn{1}{|c|}{ Group } & $\begin{array}{c}\text { Tooth Mousse } \\
\mathbf{N}=\mathbf{1 0}\end{array}$ & $\begin{array}{c}\text { Tooth Mousse/ } \\
\text { Fluoride } \\
\mathbf{N = 1 0}\end{array}$ & $\begin{array}{c}\text { Topacal C- } \\
\text { 5/Fluoride } \\
\mathbf{N = 1 0}\end{array}$ & $\begin{array}{c}\text { Control } \\
\mathbf{N}=\mathbf{1 0}\end{array}$ \\
\hline Min- max & $235-613$ & $177-609$ & $242-464$ & $368-930$ \\
\hline Mean & 468.27 & 341.40 & 357.93 & 648.03 \\
\hline SD & 102.07 & 146.367 & 76.32 & 176.71 \\
\hline $\begin{array}{l}\text { F test } \\
\text { P value }\end{array}$ & \multicolumn{5}{|c|}{11.57} \\
\hline
\end{tabular}

*: Statistically significant at $\mathrm{p} \leq 0.05$

Table 2: Basic statistics showing the comparison of the mean area of demineralization in $\mu \mathrm{m} 2 \mathrm{X} 103$ between four study groups

\begin{tabular}{|l|c|c|c|c|}
\hline Group & $\begin{array}{c}\text { Tooth } \\
\text { Mousse } \mathbf{N}= \\
\mathbf{1 0}\end{array}$ & $\begin{array}{c}\text { Tooth } \\
\text { Mousse/Fluoride } \\
\mathbf{N = 1 0}\end{array}$ & $\begin{array}{c}\text { Topacal C- } \\
\mathbf{5} / \text { Fluoride } \\
\mathbf{N = 1 0}\end{array}$ & $\begin{array}{c}\text { Control } \\
\mathbf{N = 1 0}\end{array}$ \\
\hline Min- max & $93.80-250.40$ & $68.00-252.80$ & $98.80-204.36$ & $157.84-359.20$ \\
\hline Mean & 174.80 & 142.98 & 144.26 & 258.15 \\
\hline SD & 43.74 & 60.25 & 35.34 & 68.24 \\
\hline $\begin{array}{l}\text { F test } \\
\text { P value }\end{array}$ & \multicolumn{5}{|c|}{$\begin{array}{c}10.23 \\
<0.0001 *\end{array}$} \\
\hline
\end{tabular}

*: statistically significant at $\mathrm{p} \leq 0.05$

I- Evaluation of the remineralization potential of the three techniques through the stereomicroscopic assessment of the scores of the white spot lesions. The comparison of the severity of white spots among the four study groups after two weeks and four weeks of the application showed that the complete healing was only observed in the two combination groups. The worsening of white spots to white spots with cavitations was only observed in the control group except for one case in the Tooth Mousse group. The difference between the four groups was statistically significant after two and four weeks of the application. Comparison of proportions to demonstrate the score differences between pairs of groups showed that after two and four weeks the differences were significant between the Control group and all the test groups but no difference was found between the test groups (Fig 6-11). 
Egyptian

Orthodontic Journal

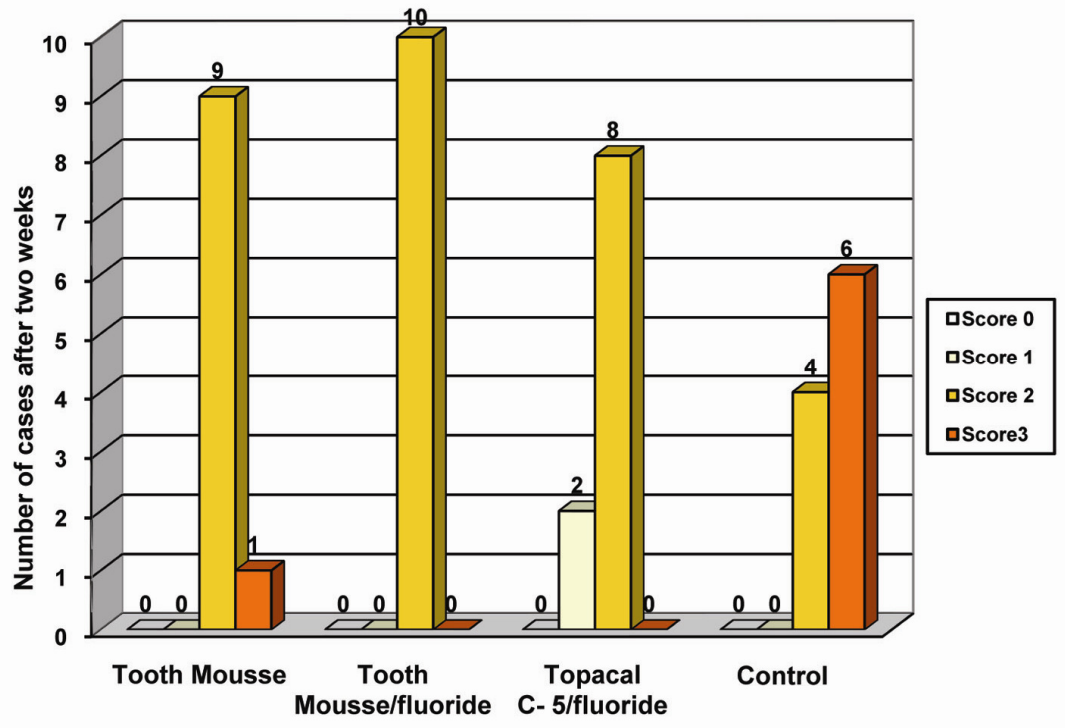

Fig 6: Bar graph showing the severity of white spot lesions among the study groups after two weeks.

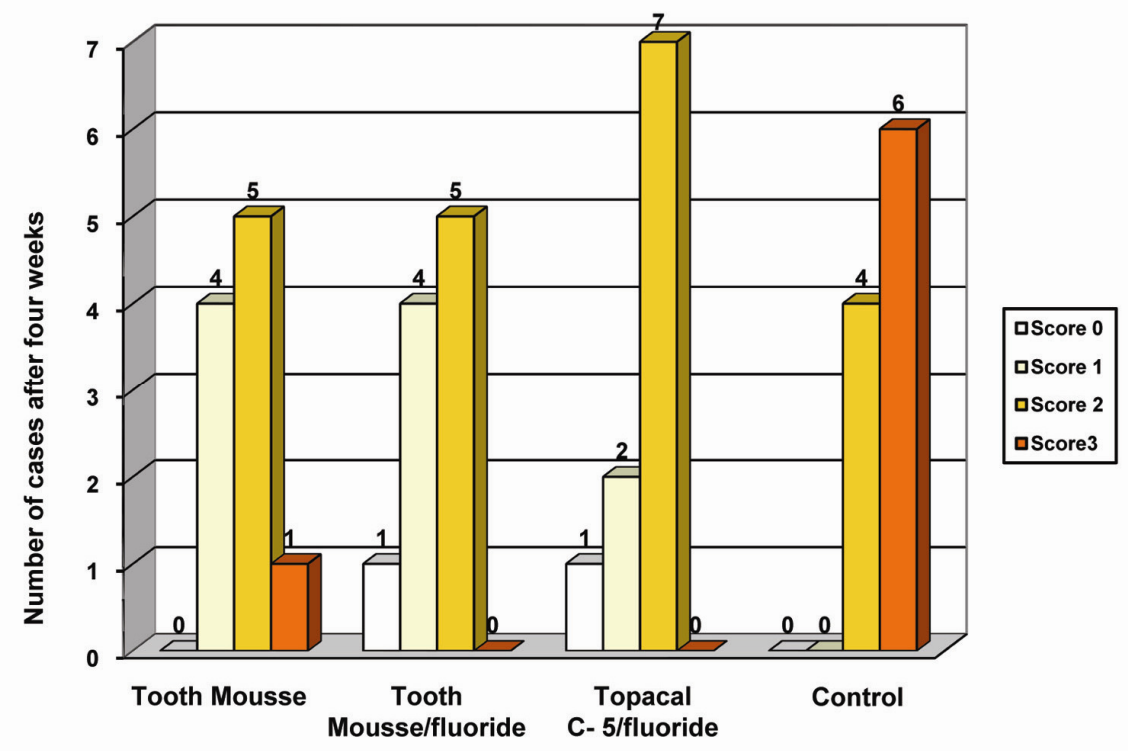

Fig 7: Bar graph showing the severity of white spot lesions among the study groups after four weeks.

Volume 36-December 2009 

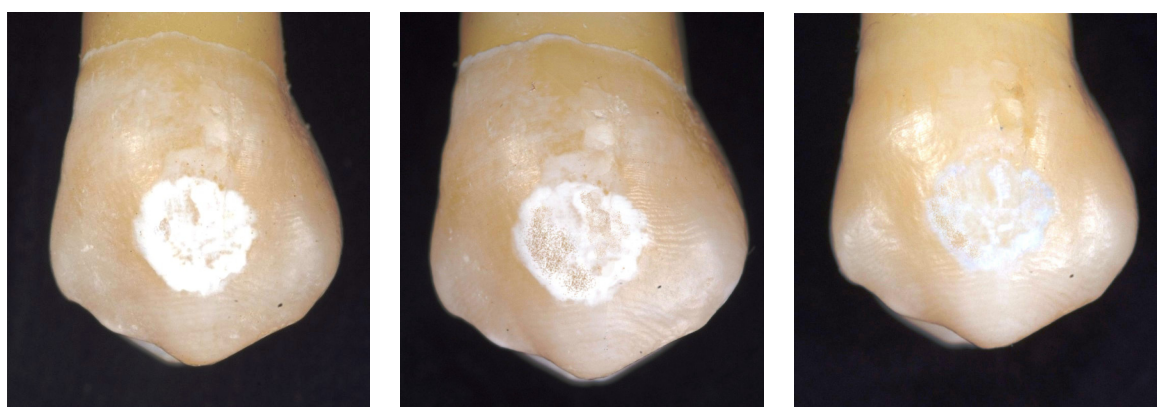

Fig 8: Stereomicroscopic pictures of a premolar in the Tooth Mousse group showing baseline score 2 (excessive white spot) before treatment (a) after two weeks score 2 (b) and after four weeks score 1 (slightly visible white spot) (c).
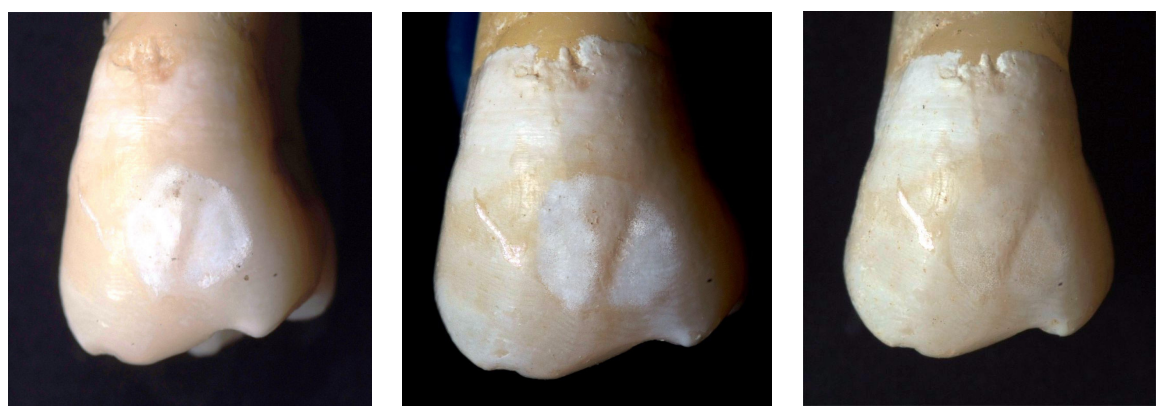

Fig 9: Stereomicroscopic pictures of a premolar in the Tooth mousse/fluoride group showing baseline score 2 (excessive white spot) before treatment (a) after two weeks still score 2 (b) and after four weeks score 0 (completely healed) (c).
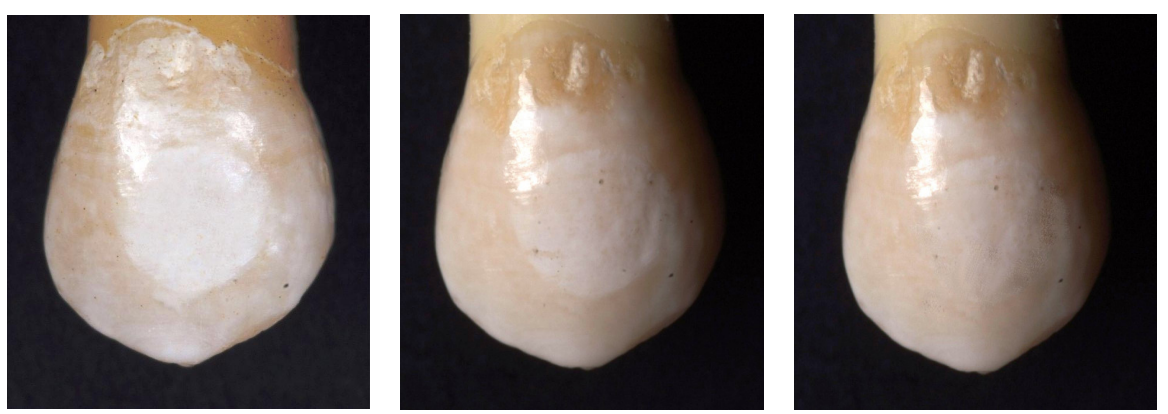

Fig 10: Stereomicroscopic picture of a premolar in the Topacal C-5/fluoride group showing baseline score 2 (excessive white spot) before treatment (a) after two weeks score 1 (slightly visible white spot) (b) and after four weeks score 0 (completely healed) (c).

Volume 36-December 2009 

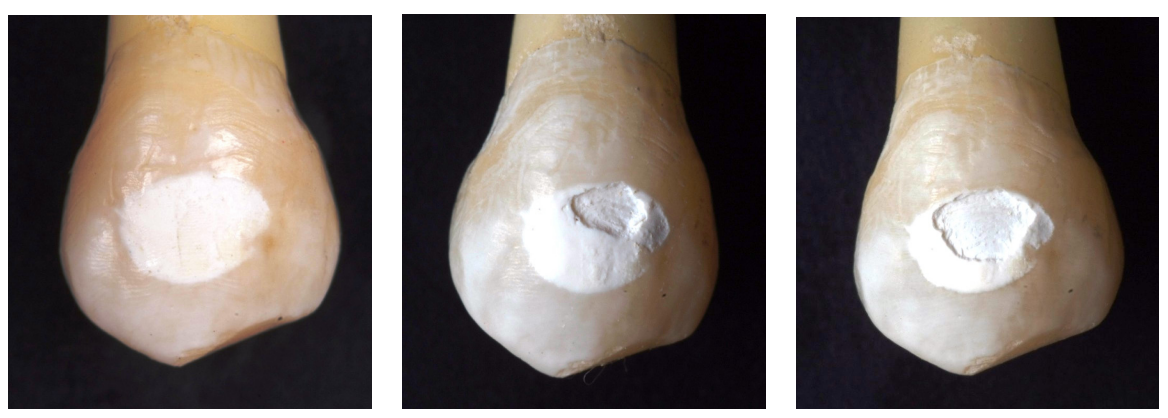

Fig 11: Stereomicroscopic pictures of a premolar in the Control group showing baseline score 2 (excessive white spot) before treatment (a) after two weeks score 3 (white spot with cavitation) (b) and after four weeks score 3 (c).

\section{DISCUSSION}

The concept of using the CPP-ACP in this study was based upon the positive results established in previous studies that proved its anticariogenicity. ${ }^{(34-41)}$ This study was designed to assess the potential benefit of the combined CPP-ACP and flouride. Two formulations of CPP-ACP were compared under the same experimental conditions with the further objective to determine what product was more synergistic with fluoride

In the first part of this study all the tested techniques proved to be effective in reducing the rate of enamel demineralization. The difference in decalcification between the Tooth Mousse group and each of the combination groups however not statistically significant showed a trend that might indicate that combining the effect of CPP-ACP and fluoride gives higher degree of protection against enamel demineralization than CPP-ACP being applied alone. The anticariogenicity of the CPP-ACP alone and the additive effect of the CPP-ACP with fluoride shown in this study are supported by the results obtained by Reynolds ${ }^{(42)}$. Reynolds suggested that the CPP-ACP localizes calcium and phosphate ions near the enamel surface in a bioavailable form for remineralization of the enamel subsurface lesions. He also suggested that the additive effect of the CPP-ACP and fluoride can be explained by the incorporation of fluoride into the CPP-ACP complex which acts as a vehicle for its delivery at the enamel surface together with the amorphous calcium phosphate. 
Conversely Pulido et $\mathrm{al}^{(43)}$ showed in heir study that the treatment with CPP-ACP did not show any effect on the inhibition of lesion progression. They also showed that there was a marginal significant difference between the CPP-ACP/fluoride treated enamel and the untreated enamel, while the high concentration fluoride reduced the lesion progression to the greatest extent. This contradicts the results obtained in the current study which proved that both the CPP-ACP and the $\mathrm{CPP}-\mathrm{ACP} /$ fluoride combinations were effective at inhibiting lesions progression as compared with the untreated teeth. However, while in the study by Pulido et al. ${ }^{(43)}$, the preparations were applied to tooth sections, in the present investigations sound teeth were treated. This difference in the method of specimen processing may account for the different

This study's findings that all of the untreated teeth in the control group exhibited white spots in the exposed zone around the brackets, while no white spots developed in the treated teeth provides evidence of the preventive effect of the tested techniques.

The enamel remineralization by the CPP-ACP found in this study is consistent with a previous study by Shen et al. ${ }^{(36)}$. Similarly Attia and Fayed $^{(35)}$ supported the findings of the current study. The proposed mechanism by Reynolds et $\mathrm{al}^{(39)}$ was the localization of the amorphous calcium phosphate at the tooth surface by the CPP depressing enamel demineralization and enhancing remineralization.

The results of the present study could not prove a significant superiority of the combination techniques over the use of the CPP-ACP alone. This was not the case in most of the previous studies that combined CPP-ACP with fluoride in one regimen. ${ }^{(41-43)}$ also Sakaguchi et $\mathrm{al}^{(40)}$ showed that the CPP-ACP when combined with fluoride has a remineralization potential significantly superior to CPP-ACP applied alone. This difference might arise from differences in the methodology employed in the different studies.

The cavitations shown in the control group demonstrates the protective effect of the three test formulations, as there was no cavitations in any of the treated teeth except for one case in the Tooth Mousse treated group. On the contrary there was an improvement in the scoring of some 
white spots in the treated teeth up to complete healing of 2 white spots one in each of the combination groups. These findings were similar to that found by Itthagarun et $\mathrm{al}^{(41)}$, but were different than that found by Ali et $\mathrm{al}^{(36)}$, who showed no cavitations in the control group, on the contrary some cases showed improvement in their scores. These contradictory findings in the untreated group may be due to the small sample size utilized in both studies.

\section{REFERENCES}

1- Gwinnett AJ, Ceen FR. Plaque distribution on bonded brackets a scanning microscopic study. Am J Orthod 1979;75:667-677.

2- Frazier MC, Southard ET, Doster MP. Prevention of enamel demineralization during orthodontic treatment: an in vitro study using pit and fissure sealants. Am J Orthod Dentofac Orthop 1996; 110 (5) 459-465.

3- Ogaard B, Rolla G, Arends J. Orthodontic appliances and enamel demineralization. Part I. Lesion development. Am J Orthod Dentofac Orthop 1988;94:68-73.

4- Gorelick L, Geiger AM, Gwinnett AJ. Incidence of white spot formation after bonding and banding. Am J Orthod 1982;1:93-98.

5- Klages U, Bruckner A, Guld Y, Zentner A. Dental esthetics, orthodontic treatment, and oral-health attitudes in young adults. Am J Orthod Dentofac Orthop 2005;128:442-9.

6- Burch JG, Lanese R, Ngan P. A two-month study of the effects of oral irrigation and automatic toothbrush use in an adult orthodontic population with fixed appliances. Am J Orthod Dentofac Orthop 1994;106:121-6.

7- Anderson GB, Bowden J, Morrison EC, Caffesse RG. Clinical effects of chlorhexidine mouthwashes on patients undergoing orthodontic treatment. Am J Orthod Dentofac Orthop 1997;111:606-12.

8- Aksoya A, Duranb N, Torogluc S, Koksald F. Short-term effect of mastic gum on salivary concentrations of cariogenic bacteria in orthodontic patients. Angle Orthod 2007;77 (1):124-8. 
9- Ogaard B, Larsson E, Henriksson T, Birkhed D, Bishara SE. Effects of combined application of antimicrobial and fluoride varnishes in orthodontic patients. Am J Orthod Dentofac Orthop 2001;120:28-35.

10- Al-Rossais FA, Abdallah HI, Zaher AR, Ibrahim HA. Plaque adherence on different orthodontic brackets and the effect of antimicrobial varnish on bacterial growth adjacent to orthodontic brackets. [Masters thesis]. Alexandria, Alexandria University 2005.

11- Wei H, Featherstone JDB. Prevention of enamel demineralization: An in-vitro study using light-cured filled sealant. Am J Orthod Dentofac Orthop 2005;128:592-600.

12- Anderson AM, Kao E, Gladwin M, Benli O, Ngan P. The effects of argon laser irradiation on enamel decalcification: An in vivo study. Am J Orthod Dentofac Orthop 2002;122:251-9.

13- Ogaard B. Prevalence of white spot lesions in 19-years-olds: A study on untreated and orthodontically treated persons 5 years after treatment. Am J Orthod Dentofac Orthop 1989;96:423-7.

14- Dimitriadis AG, Sassouni V, Draus FJ. The effects of topical fluoride applications underneath loose orthodontic bands. Angle Orthod 1974;44(1):94-99.

15- Geiger AM, Gorelick L, Gwinnett AJ, Griswold GP. The effect of fluoride program on white spot formation during orthodontic treatment. Am J Orthod Dentofac Orthop 1988;93: 29-37.

16- Mellberg JR, Charig A, Deutchman M, O’Brien W, Lass A. Effects of two fluoride gels on fluoride uptake and phosphorous loss during artificial caries formation. J Dent Res 1986;65(8):1084-6.

17- Stratemann MW, Shannon IL. Control of decalcification in orthodontic patients by daily self-administered application of a water free $0.4 \%$ stannous fluoride gel. Am J Orthod 1974;66: 273-279.

18- Boyd RL. Comparison of three self-applied topical fluoride preparations for control of decalcification. Angle Orthod 1993;63:25-30.

19- Wefel JS, Harless JD. The effect of topical fluoride agents on fluoride uptake and surface morphology. J Dent Res 1981;60(11):1842-8. 
20- O'Reilly MM, Featherstone JDB. Demineralization and remineralization around orthodontic appliances: An in vivo study. Am J Orthod Dentofac Orthop 1987;92:33-40.

21- Geiger AM, Gorelick L, Gwinnett AJ, Barbara JB. Reducing white spot lesions in orthodontic populations with fluoride rinsing. Am J Orthod Dentofac Orthop 1992;101:403-7.

22- Fahmy MA, Zaher AR, Al-Metwally HA, Aboulazm KS. Determination of fluoride release from fluoride releasing elastomeric ligature ties and its impact on microbial growth. Egyp Ortho J 2003;24:89-110.

23- Banks PA, Chadwick SM, Asher-McDade C, Wright JL. Fluoride-releasing elastomerics - a prospective controlled clinical trial. Eur J Orthod 2000; 22: 401-7.

24- Vivaldi-Rodrigues G, Demito CF, Bowman SJ, Ramos AL. The effectiveness of a fluoride varnish in preventing the development of white spot lesions. World J Orthod 2006;7:138-144.

25- Todd MA, Staley RN, Kanellis MJ, Donly KJ, Wefel JS. Effect of fluoride varnish on demineralization adjacent to orthodontic brackets. Am J Orthod Dentofac Orthop 1999;116: 159-67.

26- Gorton J, Featherstone JDB. In vivo inhibition of demineralization around orthodontic brackets. Am J Orthod Dentofac Orthop 2003; 123:10-13.

27- El-Kholy AS, Abulazm S, Zaher AR, Kawana K. In vitro study of the effect of glass ionomer cement on early enamel carious lesions. [Masters thesis], Alexandria, Alexandria University, 1998.

28- Kindelan JD. In vitro measurement of enamel demineralization in the assessment of fluoride leaching orthodontic bonding agents. Br J Orthod 1996;32:343-9.

29- Chadwick BL, Roy J, Knox J, Treasure ET. The effect of topical fluorides on decalcification in patients with fixed orthodontic appliances: A systematic review. Am J Orthod Dentofacial Orthop 2005;128:601-6.

30- Reynolds EC. The prevention of sub-surface demineralization of bovine enamel and change in plaque composition by casein in an intra-oral model. J Dent Res 1987;66: 1120-27. 
31- Silva MF, Burgess RC, Sandham HJ, Jenkins GN. Effects of water-soluble components of cheese on experimental caries in humans. J Dent Res 1987;66:38-41.

32- Silva MF, Burgess RC, Sandham HJ. Effects of cheese extract and its fractions on enamel demineralization in vitro and in vivo in humans. J Dent Res 1987;66:1527-32.

33- Cross JK, Hug NL, Palamara JE, Perich JW, Renolds EC. Physiochemichal characterization of casein phosphopeptide-amorphous calcium phosphate nanocomplex. J Biol Chem 2005; 280(5):15362-9.

34- Reynolds EC. Remineralization of enamel subsurface lesions by casein phosphopeptide-stabilized calcium phosphate solutions. J Dent Res 1997;76:1587-1595.

35- Attia KH, Fayed MS. Effect of phosphoprotein-calcium phosphate complexes on etched demineralized enamel. Egyp Dent J 2005;51:777-888.

36- Ali PNM, Zaher AR, Rasslan HS, Ismail HA. Study of the effect of topically applied oral gel formulas in the prevention and treatment of early enamel decalcification (in vitro study). [Masters thesis], Alexandria, Alexandria University, 2007.

37- Shen P, Cai F, Nowicki A, Vincent J, Reynolds EC. Remineralization of enamel subsurface lesions by sugar free chewing gum containing casein phosphopeptide-amorphous calcium phosphate. J Dent Res 2001;80(12):2066-70.

38- Mazzaoui SA, Burrow MF, Tyas MG, Dashper SG, Eakins D, Renolds EC. Incorporation of casein phosphopeptid-amorphous calcium phosphate into a glass-ionomer cement. J Dent Res 2003;82 (11): 914-918.

39- Reynolds EC, Cain CJ, Webber FL, Riley PF, Johnson IH, Perich JW. Anticariogenicity of calcium phosphate complexes of tryptic casein phosphopeptides in the rat. J Dent Res 1995;74: 1272-9.

40- Sakaguchi S, Kato S, Sato T, Kariya S, Nagao S, Chen L. Remineralization potential of CPP-ACP and its synergy with fluoride. IADR conference Brisbane 2006. 
41- Itthagarun A, Kumar N, King N. Remineralization of calcium phosphopeptide-amorphous calcium phosphate (CPP-ACP) on caries-like lesions. IADR conference Australia 2007.

42- Reynolds EC, Cochrane NJ, Shen P, Cai F, Walker GD, Morgan MV, Reynolds C. Improved plaque uptake and enamel remineralization by fluoride with CPP-ACP. IADR conference Brisbane 2006.

43- Pulido MT, Wefel JS, Hernandez MM, Qian F, Hogan MM, Harless JD. In-vitro remineralization effect of CPP-ACP with fluoride in enamel lesions. IADR conference Orlando, Florida 2006. 